\title{
A CONTRIBUTION TO THE GADAMER-LONERGAN DISCUSSION
}

\author{
Michael Baur \\ University of Toronto
}

one important element in Lonergan's philosophical work is the attempt to demonstrate the essential continuity between Aristotle's thought and the explanatory viewpoint of modern science. Among other things, this attempt is meant to serve a two-fold purpose: first of all, to defend both Aristotle's intellectualist metaphysics and the explanatory aspirations of modern science over against the caricatured representations of each which grew out of the Renaissance debate between the Aristotelians and the proponents of modern science; and secondly, to demonstrate the intrinsic limitations of modern scientific humanism in much the same way that Aquinas tried to demonstrate the essential incompleteness of Aristotle's non-Christian world view.

Now Gadamer would not deny that there is an essential continuity in thought from Aristotle to modern science; in fact, he explicitly affirms such a continuity. And like Lonergan, Gadamer insists that modern science must play a legitimate, though restricted, role within contemporary culture. Given these and other important similarities between Gadamer and Lonergan [1], it may be difficult to see just where the grounds for possible disagreement lie. As a result, Gadamer's reservations concerning Lonergan's philosophical project may appear to be somewhat puzzling. In what follows, I shall try to shed light on some of the reasons for Gadamer's reservations.

one clear difference between Gadamer and Lonergan is to be seen in their diverging evaluations of that trend in thought which begins with Aristotle and finds its latest expression in the explanatory perspective of modern science. Like Lonergan, Gadamer can appreciate some positive aspects of the Aristotelian appropriation and transformation of Plato's thought [2] . But unlike Lonergan, Gadamer asks whether this Aristotelian transformation also marks the beginning of a trend within which the fact of human finitude is given inadequate attention. For example, the Aristotelian claim that philosophy can mediate real knowledge, and indeed real knowledge of the divinity as such, stands in contrast to what for Gadamer is Plato's more modest position, a position which at times deliberately eschews explanation in favor of story-telling myth. According to 
Gadamer, further stages in the post-Aristotelian "forgetfulness" of the limitedness of human knowledge can be seen in the medieval appropriation of Aristotle's thought for the purpose of an all-embracing speculative onto-theology, and in the more recent "alliance" between neo-Thomism and the explanatory perspective of modern science. Thus for Gadamer, philosophy has already entered "too late" onto the scene if it first adopts the explanatory perspective (which was enunciated in Aristotle's physics) and then tries to mediate knowledge about human finitude in terms borrowed from this explanatory perspective itself. To meet the problem at its roots, one must go "behind" both the modern and the medieval world-views to a time before human thought started to find itself so "empowered" by Aristotle's explanatory "morphology" [3].

Gadamer's reservations concerning the Aristotelian legacy can be better understood with reference to a more current issue, namely the question concerning how the restriction of science's role within culture is to be adequately understood and mediated. According to Gadamer, the restriction of the explanatory perspective operative in both the natural and human sciences can be adequately mediated only from a standpoint external to the explanatory perspective itself. Because there is no such thing as the "self-limitation of science," we must learn to live in "two worlds," one governed by the canons of possible explanation, and the other guided by the postulates of practical reason, postulates which are entirely incommensurate with any possible theorizing or "explanation."

According to Gadamer, the philosophical tradition after Aristotle has increasingly overlooked what for the Greeks (including Aristotle) was simply presupposed, namely the primacy of non-explanatory, practical knowledge. Within the tradition of Christian Aristotelianism, for example, there has been a tendency to talk of faith and the limitedness of a purely explanatory viewpoint, yet still from within the explanatory framework itself. Thus in spite of an Augustinian moment in his thought, Aquinas still suggests that a non-Christian explanatory comportment to the world would suffer from an internal lack or incompleteness which ultimately calls for christian faith [4].

The same tendency is to be found in Lonergan's own work. In a passage that may remind one even of Hegel, Lonergan speaks of the intrinsic capacity of scientific humanism to acknowledge and transcend its own limitedness: 
The humanist viewpoint loses its primacy, not by some extrinsic invasion, but by submitting to its own immanent necessities. For if the humanist is to stand by the exigencies of his own unrestricted desire [to know], if he is to yield to the demands for the openness set by every further question, then he will discover the limitations that imply man's incapacity for sustained development, he will acknowledge and consent to the one solution that exists and, if that solution is supernatural, his very humanism will lead beyond itself. [5]

of course, Lonergan is not saying that faith can somehow be "derived" from a strictly explanatory, scientific world-view, or that the higher integration needed to deal with the problem of moral impotence can be achieved without the initiative of God. But Lonergan is claiming that a genuinely open explanatory (or "scientific") world-view as such will be able to acknowledge its own limits, and that the need for self-limitation and transcendence can be understood, articulated, and mediated intellectually by that explanatory world-view itself. (Lonergan's own thought is meant to be a concrete example of such an explanatory world-view which points beyond itself.)

For Lonergan, then, there exists the possibility of a single explanatory world-view which can acknowledge and articulate the limitations of scientific humanism, as well as the need for transcending them through some form of faith. More specifically: the Lonerganian scheme claims to mediate knowledge concerning the human will [6] and the problem of moral impotence and evil which results from human freedom; as well as knowledge concerning a benevolent and omnipotent and personal God who provides a solution to the problem of evil. In another passage reminiscent of Hegel, Lonergan alludes to the possibility of such a comprehensive scheme:

- . within this metaphysical context it has been found possible, I believe, to offer a single integrated view that finds its point of departure in classical method yet embraces biology, the psychology of behaviour and depth psychology, existentialist reflection upon man, and fundamental elements in the theory of individual and social history, of morals and asceticism, of education and religion. [7]

Now one of the most impressive features of Lonergan's philosophy may very well be its purported capacity to integrate so many different phenomena within a single explanatory perspective, yet without resorting to any form of reductionism. However, it is precisely this urge towards comprehensive philosophical integration which Gadamer would reject as the human, all too human desire to live again in one world, when such is no 
longer possible. From a biographical point of view, one can understand quite well just why Gadamer -- who was influenced very early on by Kierkegaard and Dostoyevsky and a bit later by Heidegger -- would want to resist such theoretical talk (no matter how nuanced) concerning apparently everything from the law of falling bodies to the human will and the existence of God. But the question still remains: what good reason does Gadamer have for denying the possibility of explanatory knowledge concerning the human will, the problem of moral impotence, and the existence of God, and therefore for denying the possibility of the "self-limitation" of even a genuinely open humanistic explanatory world-view, as Lonergan suggests? [8]

A significant issue separating Gadamer and Lonergan, then, is the question of whether one can attain meaningful theoretical knowledge concerning the human will, the problem of evil, or the existence of God -- knowledge on the basis of which a non-selftranscending scientific humanism is supposed to be able to acknowledge its own limitations. To keep the following discussion within reasonable limits, I will focus exclusively on the claim to theoretical knowledge concerning the human will [9]. It must be emphasized here that the issue is not whether the freedom of the will can be proven (for Lonergan does not attempt any such proof); and the issue is not whether the problem of evil necessarily implies a supernatural solution to it (for Lonergan does not claim this, either). The crucial issue is not even the question of how, ontologically speaking, a scientific humanism is supposed to transcend itself (for Lonergan would want to say that such self-transcendence would depend, in the final analysis, on God's grace). The issue here rather is whether an explanatory scientific humanism can even begin to acknowledge grounds for its own self-transcendence, i.e. whether one can intellectually mediate knowledge concerning those things which are supposed to imply the incompleteness of scientific humanism.

In my conversation with Gadamer, I attempted to suggest the possibility of a (neo-Thomist) conception of matter or materiality which fits into an explanatory scheme which, in turn, could allow for the fact of human freedom. To simplify greatly, matter is said to be the principle of individuation, i.e. it is the "reason" why there can be several different instances of the same form. Furthermore, since generalization in the sciences requires that there be several different instances of the same 
form, one might say that matter is also -- though indirectly -. a principle of generalization in the sciences. It follows that those beings which are less determined by a material component will be less subject to scientific generalization. For example, chemical elements and compounds demonstrate a certain degree of "freedom" from underlying physical manifolds, plants and animals from underlying chemical manifolds, and human beings from the underlying biological and even psychological manifolds. Accordingly, the possibilities for scientific generalization decrease progressively as one moves "upwards" along the hierarchical "ladder of the sciences": while the laws of physics apply to all bodies whatsoever, one would be very hard pressed to articulate some kind of non-tautological "law" which could apply to all human beings as such [10].

Now Gadamer would not reject the preceding explanatory scheme out of hand, provided that "matter" here is understood as a bare "limit-concept," a concept which does not designate anything positive in itself, and therefore does not yet imply the peculiarly modern determinations of space (extension) and time (duration). However, the above scheme can help to articulate the meaning of human freedom only negatively, i.e. as freedom from determination by underlying material manifolds. If human freedom is not to consist simply in arbitrariness, i.e. in its not being subject to any law whatsoever, then there must be a positive aspect to human freedom as well. According to Lonergan, there is such a positive aspect, and we can mediate knowledge of it intellectually. Lonergan explicitly states that spiritual reality such as will is not only intelligent, but also intelligible, i.e. the possible "object" (though not in any degrading, "objectivistic" sense) of theoretical knowledge. in deliberate contrast to kant on the issue of freedom and morals, Lonergan writes that one not only may speak meaningfully about what is implied by the word "ought," but also may do so within the sphere of "speculative intelligence and reason" [11]. Since Gadamer would have certain reservations about the second claim here, we have to look a bit further into some of Lonergan's reasons for making it.

How, for lonergan, is spiritual reality such as the human will intelligible? As Lonergan writes,

spiritual reality has intelligibility, not through subjection to law, but by its native intelligence, and while spiritual reality is manifested through the higher sys- 
ly -

that

onent

mple, ee of imals $m$ the olds. ation erarapply ed to apply

1atory ood as gnate imply and ticue. as S. If e. in ast be ng to ediate s that also n any e. in prals, about vithin Since claim rgan's human ubjecwhile ys- tematization or order it imposes on lower levels of being, still that systematization or order is not imposed upon spiritual reality, as the law of inverse squares upon masses, but is generated by practical insights, rational reflection, and decision. [12]

Thus for Lonergan, spiritual reality such as the will is intelligible, not through its subjection to law, but "through the higher systematization or order it imposes on lower levels of being." But one might well ask whether this is really an adequate representation of the intelligibility of the human will when the will -- by virtue of its very freedom -- can confer further disorder as well as order upon the lower levels of being. Is the only difference between the human will (which can impose order on lower levels of being) and chemical process (which can also impose order on lower levels of being) the fact that the human will, in contrast to chemical process, is not subject to any further systematization through a still higher order of being? One might want to suggest that the real difference lies in the fact that spiritual reality such as the human will is intelligent as well as intelligible. Unfortunately, such an answer does not help here, if this "intelligence" (just like the "intelligibility") of the human will is supposed to be manifested in the capacity of the will to confer order upon lower levels of being. By implicitly deriving its standard from those lower orders of being upon which order can be conferred, Lonergan's "speculative" discussion of the will apparently fails to articulate adequately what is truly distinctive about the human will. And because of this failure, the Lonerganian theoretical scheme seems capable of articulating only half of the meaning of the human will, i.e. will insofar as it factually succeeds in conferring order, and not disorder, upon lower levels of being.

The reader who is familiar with Martin Heidegger's Being and Time (which influenced Gadamer tremendously) should begin to understand by now the essential issue behind the objection here: the problem is that Lonergan comes too close to articulating the intelligibility of human spiritual reality (or "Dasein," in Heidegger's terminology) on the basis of those intelligible orders within the worlds of nature and artifacts. Of course, Lonergan would want to draw a sharp distinction between the spiritual reality which we are and the non-spiritual reality of things in the world. But the theoretical basis upon which he 
tries to make this distinction would be inadequate for Heidegger or Gadamer. For Lonergan, the intelligibility of the will is manifested (and thus verifiable) only insofar as the will confers order upon lower levels of being, i.e. only insofar as its acts are commensurate with the intelligible orders which can inhere in the lower levels of being. Because of this, Lonergan's scheme is capable of articulating only "one side" of the spiritual reality called will -- its ability to confer order on lower levels of being -- and therefore is essentially incapable of articulating this spiritual reality in its real distinctiveness.

of course, the Lonerganian would want to point out the metaphysical dimension to the problem here: because unintelligibility prescinds from being, it would be a mistake to suppose that the unintelligent, unreasonable, irresponsible act of will -- the act which confers disorder upon existing reality -- is a positive instance of being which can be understood as such. Such an act of will (and the disorder which results from it) represents nothing positive in itself, but is instead an instance of potential being or potential goodness. It would then follow that there is nothing wrong with a theoretical account of the will which can articulate only the "positive side" of the human will, i.e. the will insofar as it confers further order upon reality. After all, everything that prescinds from intelligibility prescinds also from being.

Now from Heidegger's and Gadamer's point of view, the Lonerganian would be quite justified in pointing out the essential connection between this discussion of spiritual reality and its further metaphysical dimension. However, this essential connectedness can function as a two-edged sword. Either one can maintain (as Lonergan does) the claim to a potentially unlimited explanatory scope and argue that that which necessarily eludes all possible explanation must also prescind from being as such; or else, one can argue that those matters of fact which defy all possible explanation attest to the inadequacy of the explanatory framework as such. In the latter case, one might speak of the need to "overcome metaphysics" (as Heidegger does) or (following Gadamer) of the need to live in two worlds, one of which necessarily remains incommensurate with all forms of possible "explanation" [13]. But common to both the Heideggerian and Gadamerian approaches is the conviction that an explanatory world-view is necessarily inca- 
gger

1 is will

$r$ as

can ner-

the

$r$ on

able

ive-

the tele to act lity d as from d an vould ical tive ifers presthe the itual this nord. to a that also those st to the metaneed ncomBut $s$ the nca-

pable of "explaining" -- or even acknowledging -- the grounds for its own limitation.

I have tried briefly to explicate this putative failing of the explanatory world-view by reference to Lonergan's thought concerning the supposed intelligibility of spiritual reality, such as the human will. If Lonergan's "speculative" framework cannot adequately articulate that which makes this spiritual reality truly distinctive, then how is the distinctiveness (and therefore inviolability) of this spiritual reality to be ensured? For Gadamer, this distinctiveness cannot be demonstrated or even mediated intellectually. Any attempt to do so would already imply a kind of violation of the inviolable. Of course, the claim here is not that we can know nothing at all concerning the spiritual reality which we are [14]; the claim is rather that what we may know concerning this distinctive spiritual reality cannot be mediated through any theory or "actus signatus." To express it in Kantian terminology: knowledge concerning the distinctive spiritual reality which we are can be had only through the ideas of practical reason.

If the preceding reflections have succeeded in shedding some light on the reasons for Gadamer's reservations vis-à-vis Lonergan's neo-Thomism, it has not been possible here to examine to what extent such reservations are really justified. By this, however, I am not suggesting that the preceding attempt has been "value-neutral." In my attempt to make Gadamer's position a bit more understandable with reference to Lonergan, I have also tried to point out some of those objections which Lonerganians today would have to meet if Lonergan's project is to remain viable in light of Gadamer's post-Heideggerian thought.

\section{NOTES}

I would like to thank Professor Gadamer for discussing several aspects of this essay with me. Of course, I remain solely responsible for the content of this essay.

[1] Some of these similarities include, for example: the emphasis on a kind of non-objectifying concomitant awareness which accompanies all of our conscious acts; the attempt to "go behind" all logics and methodologies to their dynamic source in the ever-self-transcending questioning and answering of the human subject herself or himself; the insistence on the need for some kind of mediation between what Lonergan terms the "classicist" and "empirical" notions of culture, or between what Gadamer refers to as "essentialism" and "the experiential standpoint of the modern age."

[2] It must be kept in mind, however, that those things which Gadamer appreciates in Aristotle are not always the same 
as those which Lonergan appreciates, and vice versa. And although both Gadamer and Lonergan borrow heavily from Aristotle for their own purposes, the fact remains that these purposes are often quite divergent. Consider, for example, Gadamer's and Lonergan's diverging approaches to Aristotle's writings concerning how we humans come to know. Lonergan emphasizes that sudden and unexpected occurrence which he calls insight, which (in Lonergan's interpretation) Aquinas called "intelligere," and which (according to Lonergan) Aristotle articulated as the grasp of the form in the image ("eidos en phantasmati," De Anima III, 7). Lonergan's intention is to unfold the implications of this notion of understanding as they apply, not only to the realm of common sense where practical insights occur, but also to mathematics and the natural sciences, where insight makes possible the formulation of implicit definitions, theorems, and generalized laws of nature. In contrast, Gadamer treats as paradigmatic Aristotle's discussion of our coming to know on the analogy of the fleeing army (Posterior Analytics II, 19). Here, our knowing is seen, not as the product of a sudden mental occurrence (which Lonergan calls insight), but as the gradual result of repeated experience. Gadamer appeals to this paradigm of knowing in order to articulate what for him is the foundation of all our knowing whatsoever: our practically-oriented "beingin-the-world."

[3] Gadamer uses the term "morphology" in his article, "Bürger zweier Welten," in Das Erbe Europas (Frankfurt am Main: Suhrkamp Verlag, 1989), p. 111.

[4] Gadamer would want to argue further that the question concerning the incompleteness or "self-limitation" of a purely faith-less explanatory world-view never arose for the Greeks as a problem, not so much because they were pagans, but because the Greeks already presupposed and accepted without explicit mention the primacy of practical, lived knowledge over all forms of explanation. (In this sense, the Greeks lived still in "one world.") The need to address the problem explicitly in the Middle Ages and today represents for Gadamer not so much a positive development as a kind of "fallenness" into a state of "being-in-two-worlds" - - a state which contemporary thinkers are still trying (in vain, for Gadamer) to overcome.

[5] Bernard J.F. Lonergan, Insight: A Study of Human Understanding (New York: Harper and Row, 1978), p. 728 .

[6] Because of his admiration for early Greek thinking, Gadamer himself would be reluctant to employ the term "will" (see interview). In my own presentation of a "Gadamerian critique" of Lonergan, I have nevertheless retained this term (1) for the sake of stylistic convenience, and (2) because Lonergan uses this term. A term such as "Dasein" would be more consistent with Gadamer's way of thinking, but this term would be misleading in the present context. In order to use a term somewhat more amenable to both the Lonerganian and Gadamerian discourse, one could refer to "the spiritual reality which we are"; but it would have been too cumbersome to employ this phrase consistently throughout this essay.

[7] Lonergan, Insight, p. 479.

[8] The "therefore" in this question makes sense if, as Lonergan suggests, the capacity of a scientific humanism to acknowledge and transcend its own limitations is bound up with the possibility of theoretical knowledge concerning the human 
And

otle

i are

and

ern-

idden

(in

and

rasp

III,

this

im of

o to

nakes

and

$s$ as

n the

lere,

ental

adual

adigm

ation

eing-

icle, Main:

stion urely ks as e the ntion ns of "one the posite of s are

Human

king, will" erian term cause more would term erian ch we this

$f$, as sm to with uman

will, the problem of moral impotence and evil, and the existence of God. (See, for example, the above-quoted passage from page 728 of Insight.)

[9] This is not to suggest that for Lonergan such knowledge concerning the human will directly implies the need for the transcendence of a scientific humanism. However, Lonergan's account of moral impotence -- which, along with his discussion of God, is supposed to show the need for the transcendence of scientific humanism -- necessarily presupposes theoretical knowledge concerning the human will and what makes the will truly distinctive. Thus if the need for the transcendence of scientific humanism is to be intellectually mediated as Lonergan suggests, then such knowledge concerning the human will must be possible.

[10] To put it differently, higher development implies a higher degree of differentiation.

[11] Lonergan, Insight, p. 600. [12] Ibid., pp. 617-618.

[13] Gadamer would argue that this implies a kind of "irrationalism" only if one presupposes in the first place an unjustifiably restricted notion of rationality.

[14] If this were the claim, then it could be easily criticized; for such a claim would rest on a performative contradiction: "I know enough about $\mathrm{X}$ to know that $I$ cannot know anything at all about $\mathrm{x} . "$ 